\title{
Summary of guidelines for infection prevention and control for flexible gastrointestinal endoscopy
}

\author{
Lawrence Hookey MD ${ }^{1}$, David Armstrong MB BChir ${ }^{2}$, Rob Enns MD³, \\ Anne Matlow $\mathrm{MD}^{4}$, Harminder Singh $\mathrm{MD}^{5}$, Jonathan Love $\mathrm{MD}^{6}$
}

L Hookey, D Armstrong, R Enns, A Matlow, H Singh, J Love. Summary of guidelines for infection prevention and control for flexible gastrointestinal endoscopy. Can J Gastroenterol 2013;27(6):347-350.

BACKGROUND: High-quality processes to ensure infection prevention and control in the delivery of safe endoscopy services are essential. In 2010, the Public Health Agency of Canada and the Canadian Association of Gastroenterology (CAG) developed a Canadian guideline for the reprocessing of flexible gastrointestinal endoscopy equipment.

METHODS: The CAG Endoscopy Committee carefully reviewed the 2010 guidelines and prepared an executive summary.

RESULTS: Key elements relevant to infection prevention and control for flexible gastrointestinal endoscopy were highlighted for each of the recommendations included in the 2010 document. The 2010 guidelines consist of seven sections, including administrative recommendations, as well as recommendations for endoscopy and endoscopy decontamination equipment, reprocessing endoscopes and accessories, endoscopy unit design, quality management, outbreak investigation and management, and classic and variant Creutzfeldt-Jakob Disease. DISCUSSION: The recommendations for infection prevention and control for flexible gastrointestinal endoscopy are intended for all individuals with responsibility for endoscopes in all settings where endoscopy is performed.

Key Words: Endoscopy; Gastrointestinal; Guideline; Infection; Prevention

$\mathrm{R}$ ecent, widely publicized incidents have highlighted continuing Rconcerns that infections may be transmitted from patient to patient during routine flexible gastrointestinal endoscopic procedures (1). Recognizing these concerns the Canadian Association of Gastroenterology (CAG) and the Public Health Agency of Canada (PHAC) collaborated in the development of a Canadian guideline for the reprocessing of gastrointestinal endoscopy equipment. Guideline development was facilitated by unrestricted grants from industry and support from the CAG and PHAC. High-quality processes to ensure infection prevention and control are essential components of the broader strategy to ensure delivery of safe endoscopy services as addressed in the recent CAG consensus guideline on safety and quality indicators in endoscopy (2).

The Infection Control Guideline Steering Committee of PHAC develops national infection prevention and control guidelines to provide evidence-based recommendations to complement provincial/territorial governments' efforts in monitoring, preventing and controlling health care-associated infections. The PHAC infection prevention and control guideline for flexible gastrointestinal endoscopy and flexible

\section{Sommaire des lignes directrices sur la prévention et le contrôle des infections en cas d'endoscopie gastro-intestinale souple}

\begin{abstract}
HISTORIQUE : Il est essentiel d'adopter des processus de qualité pour garantir la prévention et le contrôle des infections dans la prestation de services d'endoscopie sécuritaires. En 2010, l'Agence de la santé publique du Canada et l'Association canadienne de gastroentérologie (ACG) ont préparé des lignes directrices canadiennes pour le retraitement des appareils souples d'endoscopie digestive.

MÉTHODOLOGIE : Le comité de l'endoscopie de l'ACG a soigneusement analysé les lignes directrices de 2010 et en a préparé un sommaire.

RÉSULTATS : Les chercheurs ont souligné les principaux éléments liés à la prévention et au contrôle des infections transmises par les appareils souples d'endoscopie digestive contenus dans chacune des recommandations du document de 2010. Les lignes directrices de 2010 se divisaient en sept parties, y compris les recommandations administratives, les recommandations sur les instruments d'endoscopie et l'équipement de décontamination, le retraitement des endoscopes et des accessoires connexes, l'aménagement d'une unité d'endoscopie, la gestion de la qualité, les enquêtes sur les éclosions et la gestion des éclosions ainsi que la maladie de Creutzfeldt-Jakob classique et sa variante.

EXPOSÉ : Les recommandations relatives à la prévention et au contrôle des infections transmises par les appareils souples d'endoscopie digestive sont destinées à toutes les personnes responsables des endoscopes, quel que soit le lieu où l'endoscopie est effectuée.
\end{abstract}

${ }^{1}$ Division of Gastroenterology, Queen's University, Kingston; ${ }^{2}$ Division of Gastroenterology, McMaster University, Hamilton, Ontario; ${ }^{3}$ St Paul's Hospital,

University of British Columbia, Vancouver, British Columbia; ${ }^{4}$ Women's College Hospital, University of Toronto, Toronto, Ontario;

${ }^{5}$ Internal Medicine, University of Manitoba, Winnipeg, Manitoba; ${ }^{6}$ Division of Gastroenterology, University of Calgary, Calgary, Alberta

Correspondence: Dr Lawrence C Hookey, Gastroenterology Division, Sydenham 4, Hotel Dieu Hospital, 166 Brock Street, Kingston, Ontario K7L 5 G2.

Telephone 613-544-3400 ext 2292, fax 613 544-3114, e-mail hookeyl@hdh.kari.net

Received for publication January 17, 2013. Accepted February 18, 2013 
Under the auspices of PHAC's Infection Control Guideline Steering Committee, an interdisciplinary Guideline Working Group, including clinical microbiologists, endoscopy nurses, gastroenterologists, hospital epidemiologists, infectious disease specialists, infection prevention and control professionals, biomedical technicians and representatives of the medical instrument reprocessing sector, was assembled to develop the guideline. This multidisciplinary group also reflected a balanced representation of the regions of Canada.

As a partner in the process, we (the CAG Endoscopy Committee) aim to provide practicing physicians with an executive summary of the guideline's contents. The guideline consists of seven sections, summarized below, which highlight the key elements relevant to infection prevention and control for flexible gastrointestinal endoscopy. For more comprehensive data and references, we encourage readers to review the original document available online (3).

\section{SECTION 1: ADMINISTRATIVE RECOMMENDATIONS}

A robust administrative framework is essential for the successful adoption and implementation of effective infection prevention and control processes. Endoscopy facilities and, where appropriate, the overseeing health care facilities must be fully aware of the appropriate policies they should have detailed written policies and procedures that address all aspects of the handling (ie, cleaning, reprocessing and storage) of flexible endoscopes and accessories, which are consistent with current standards and recommendations.

- The endoscopy facilities' policies and procedures should specifically address the following:

- Single-use equipment.

- Responsibilities of management and staff involved in endoscopy service delivery.

- The qualification, education and training requirements for all personnel handling endoscopes.

- The responsibility of the endoscopist for notifying all involved personnel if there is any possibility of a transmissible infection (eg, tuberculosis, hepatitis, HIV, Clostridium difficile) even though universal precautions are promoted.

- The recall of any improperly reprocessed equipment, evaluation of patient risk, notification of all affected individuals or institutions, and notification of appropriate regulatory bodies.

- Regular review and revision, at least annually, of all policies and procedures, in collaboration with appropriate support programs.

- All health care facilities in which endoscopy is performed should have ongoing access to appropriate support programs, such as:

- Infection prevention and control in health care facilities.

- Occupational health and safety.

- Personnel training and education in the handling of flexible endoscopes and accessories.

\section{SECTION 2: RECOMMENDATIONS FOR ENDOSCOPY} AND ENDOSCOPY DECONTAMINATION EQUIPMENT

The endoscopes, light sources and endoscopic accessories used every day in practice are essentially only the most visible part of what is required to appropriately equip an endoscopy unit.

- Medical equipment or devices intended for use in an endoscopy facility should be purchased only under the following circumstances:

- They can be cleaned/reprocessed according to applicable, recommended standards.

- They meet the requirements of the institution's infection prevention and control program.

- They are fully supported by the manufacturer's provision of comprehensive information manuals on design, assembly, use, cleaning/reprocessing, staff training and audit processes for equipment handling.
- Maintenance and repair of medical equipment or devices intended for use in an endoscopy facility should be performed only by qualified personnel using original equipment manufacturer parts.

- Automatic endoscope reprocessors (AERs) should be purchased only if they meet the following criteria:

- They are licensed for sale in Canada.

- All endoscope channels and internal surfaces can be irrigated with high-level disinfectant or chemical sterilant.

- They drain completely after each wash cycle, leaving no reservoirs.

- Disinfectant is handled appropriately, with complete drainage between cycles for single-use disinfectant or daily monitoring, using appropriate test strips, for reusable disinfectant.

- The manufacturer specifically identifies the brands and models of endoscopes and accessories that can be reprocessed effectively, as well as any potential limitations to reprocessing.

- The manufacturers' reprocessing instructions for endoscopes and the AER have been compared and any conflicts resolved before the first reprocessing.

- The manufacturer understands and meets its obligation to report any defect or circumstance that might affect endoscope reprocessing.

- The use of AERs should adhere to detailed, written policies and procedures to ensure that:

- Any incomplete or interrupted AER cycle is repeated immediately.

- Appropriate personnel associated with the endoscopy facility routinely review Health Canada's advisories, warnings, and recalls about marketed health products, Emergency Care Research Institute reports, manufacturer alerts and the scientific literature for reports of AER deficiencies that may lead to infection.

- An endoscope that requires repairs must be disinfected properly or, if this is not possible, prepared and shipped appropriately as a contaminated instrument; only then should it be sent, in accordance with applicable jurisdictional requirements, to the repairer.

- There are policies and processes for preventive maintenance of all devices and equipment.

SECTION 3: RECOMMENDATIONS FOR REPROCESSING ENDOSCOPES AND ACCESSORIES

The management of endoscope reprocessing requires strict regulation to ensure adequate cleaning and the avoidance of contamination of patients as well as other areas of the endoscopy unit. These steps must be audited regularly and adherence must be absolute. The steps involved have evolved over many years and are proven to be effective at avoiding contamination issues that may be catastrophic.

- Endoscopes should be wiped down immediately after a procedure.

- Channels should be flushed/brushed with enzymatic detergent and then flushed with water.

- Soiled endoscopes should be transported to the reprocessing area in a closed container.

- Leak testing should be performed according to manufacturer's requirements.

- All detachable components should be cleaned individually using enzymatic solution.

- Endoscopes require high-level disinfection.

- High-level disinfection is defined as the destruction of all vegetative microorganisms, mycobacteria, small or nonlipid viruses, medium or lipid viruses, fungal spores and some, but not all, bacterial spores. 
- Instruments and accessories that break the mucosal barrier require sterilization.

- Sterilization is defined as the destruction of all microbial life.

- Formulations containing glutaraldehyde or glutaraldehyde with phenol/phenate (which require adequate ventilation in accordance with Workplace Hazardous Materials Information System and Ministry of Labour regulations), orthophthalaldehyde, hydrogen peroxide, peracetic acid, or a combination of hydrogen peroxide and peracetic acid can be used to achieve high-level disinfection if the products are used as directed.

- Manual processing is discouraged.

- Endoscopes should be stored uncoiled, hanging vertically in a clean, dry, ventilated area.

- This prevents recontamination or damage.

- The maximum allowable storage time before reprocessing is required is seven days.

- Strict adherence to manufacturer's requirements for reprocessors is critical for maintenance of appropriate high-level of disinfection.

- As guidelines/requirements change, routine upgrading and reassessment of procedures are critical.

- Only instruments specifically approved for cleaning in these reprocessors should be used.

- Health Canada approval is required for all sterilants or high-level disinfectants.

\section{SECTION 4: RECOMMENDATIONS FOR ENDOSCOPY UNIT DESIGN}

The development of any endoscopy unit must take into account not only patient 'flow' to maximize efficiency but also the 'flow' of endoscopes from 'clean to contaminated' areas.

- Any areas where endoscopes are used and disinfected should be designed to provide a safe environment for patients and health care workers.

- Procedure rooms should have a separate, dedicated handwashing sink with hands-free controls.

- Reprocessing areas should be provided with a separate hand washing station.

- Workflow should proceed from 'clean to contaminated' areas, with adequate separation to minimize the risk of cross contamination.

- Endoscope reprocessing areas should be physically separate from procedure rooms.

- Clean, dry endoscope storage space is required, and should be physically separate from decontamination and cleaning areas.

- Preventing exogenous infections arising from microorganisms introduced into the patient's body by the flexible endoscope, or by the accessories used in the procedure, must be of critical concern to every endoscopist.

- The endoscopist's safety, as well as that of others involved in the procedure, must be protected.

\section{SECTION 5: RECOMMENDATIONS FOR QUALITY MANAGEMENT}

Quality management encompasses all aspects of pre- and postprocedural care including the efficiency of the endoscopy unit and reprocessing area, as well as the endoscopic procedure itself.

- Personnel assigned to reprocess endoscopes and accessories should receive hands-on training with written, device-specific reprocessing instructions for every endoscope model and AER in their area of responsibility.

- Competency should be documented by testing after completion of initial training and at least annually thereafter.

- Personnel should not be allowed to reprocess endoscopes until competency is established.
- The culture of the endoscopy unit should reflect the critical role the reprocessing personnel play in every procedure performed.

- Personal protective equipment (eg, gloves, gowns to be changed between procedures, eye protection visors and goggles) should be readily available and routinely used to protect health care workers and patients.

- N 95 respirators should be used by health care workers present during the procedure if pulmonary or laryngeal tuberculosis is suspected.

- Endoscope and AER manufacturers' written recommendations and instructions for reprocessing should be followed.

- The disinfectant/sterilizing agent should be routinely tested to ensure minimum effective concentration of the active ingredient.

- The solution should be checked at least at the beginning of each day and a log of test results maintained.

- Regardless of the minimum effective concentration, the solution should be discarded at the end of its re-use life, which may be single use.

- There should be a standard protocol at each health care facility to enable users to easily identify the endoscopes that are ready for patient use and keep them separate from contaminated endoscopes.

- A surveillance system should be established to detect potential clusters of infections associated with endoscopic procedures.

- Permanent records of use and reprocessing of endoscopes should be maintained.

- Records should include patient name, medical record number, the endoscopist, date and time of the clinical procedure, identification number and type of endoscope and AER, results of inspection and leak test and name of the person reprocessing the endoscope.

- Records will aid in the investigation of any potential outbreaks associated with the endoscopic procedures and notification of the patients and health care providers (see Sections 6 and 7).

- A record of preventive maintenance should be kept.

\section{SECTION 6: RECOMMENDATION FOR OUTBREAK INVESTIGATION AND MANAGEMENT}

Investigation and management of any potential outbreak of endoscopyrelated infection is essential to prevent further transmission and/or reoccurrence.

- If a breach in protocol for endoscope reprocessing is recognized, an assessment and investigation should be performed to determine why it occurred and how to prevent a recurrence. A risk assessment should be initiated to determine whether patient notification is required.

- If a cluster of suspected or confirmed endoscopy-related infections is identified, an investigation should be initiated to determine possible routes of transmission.

- A record should be kept of each endoscope used for each patient. This is important for any future contact tracing when possible endoscopic disease transmission is being investigated. This should be a general policy.

\section{SECTION 7: RECOMMENDATIONS FOR CLASSIC AND VARIANT CREUTZFELDT-JAKOB DISEASE}

Unique management strategies, particularly for reprocessing, are required to prevent contamination by, and transmission of, some specific infections.

- Endoscopes used for invasive (eg, biopsy) procedures in individuals with possible variant Creutzfeldt-Jakob disease (vCJD) should be removed from use or quarantined to be reused exclusively on the same individual if required. If the diagnosis is positive for vCJD then the instrument should be incinerated. 


\section{Hookey et al}

- Transmissible spongiform encephalopathy (TSE)-specific protein (pathological prion protein TSE) in $\mathrm{VCJD}$ is present in lymphatic tissue, which is prevalent in the gastrointestinal tract.

- With classic CJD, because pathological prion protein TSE has not been found in the gastrointestinal tract, gastrointestinal endoscopy alone is unlikely to be a vector for its transmission. However, if there is a risk that the endoscope could be contaminated with olfactory epithelium (neurological tissue), the endoscope should be removed from use.

- Aldehyde disinfectants should not be used to reprocess endoscopes that have been used in patients with (confirmed) classic CJD because they fix proteins.

- An instrument tracking record should be kept of each endoscope used for each patient. This is important for any future contact tracing when possible endoscopic disease transmission is being investigated. As noted in section 5, this should be a general policy.

\section{REFERENCES}

1. Ottawa private clinic behind hepatitis, HIV scare. <www.cbc.ca/ news/canada/ottawa/story/2011/10/17/ottawa-public-healthinfection-letters.html> (Accessed December 12, 2012).

2. Armstrong D, Barkun A, Bridges R, et al. Canadian Association of Gastroenterology consensus guidelines on safety and quality indicators in endoscopy. Can J Gastroenterol 2012;26:17-31.

3. Public Health Agency of Canada. Infection prevention and control guideline for flexible gastrointestinal endoscopy and flexible brochoscopy. <www.phac-aspc.gc.ca/nois-sinp/guide/endo/pdf/endoeng.pdf> (Accessed December 12, 2012).

\section{CONCLUSIONS}

Proper handling (ie, cleaning, reprocessing and storage) of flexible endoscopes and accessories is critical to ensure the safety (ie, prevent transmission of iatrogenic infection via endoscopy) of all individuals undergoing endoscopy, as well as those involved in performance of the procedures and maintenance of the endoscopy equipment.

Appropriate structure and administrative support in the endoscopy facility are essential to ensure proper handling of endoscopes.

Medical leadership, and all endoscopists, should foster a culture of safety and high standards that emphasizes the critical role that endoscope reprocessing, and the personnel who perform it, play in every procedure performed.

As gastrointestinal endoscopy services expand due to technological advances and increased demands, such as colon cancer screening programs, it is more important than ever for all providers, administrators and policy makers involved in gastrointestinal endoscopy to be aware of these recommendations.

4. Petersen BT, Chennat J, Cohen J, et al. Multisociety guideline on reprocessing flexible gastrointestinal endoscopes: 2011.

Gastrointest Endosc 2011;73:1075-84.

5. Society of Gastroenterology Nurses and Associates. Guidelines for use of high level disinfectants \& sterilants for reprocessing flexible gastrointestinal endoscopes. <www.sgna.org/Portals/0/HLD.pdf> (Accessed October 15, 2012).

6. Society of Gastroenterology Nurses and Associates. Standards of infection control in reprocessing of flexible gastrointestinal endoscopes. <www.sgna.org/Portals/0/sgna stand_of_infection control_0712_FINAL.pdf> (Accessed October 15, 2012). 


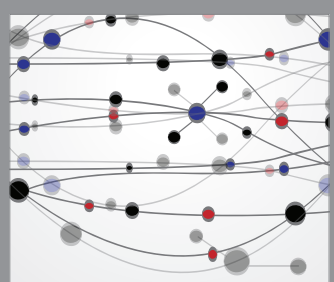

The Scientific World Journal
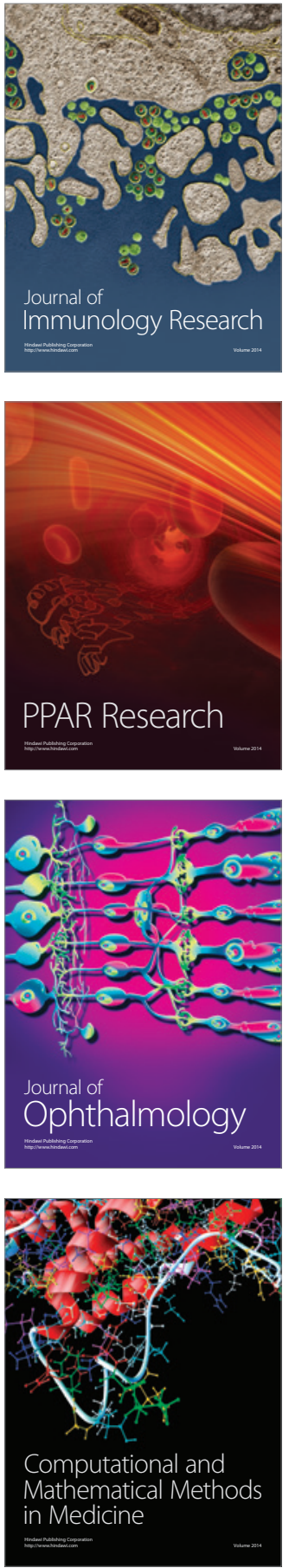

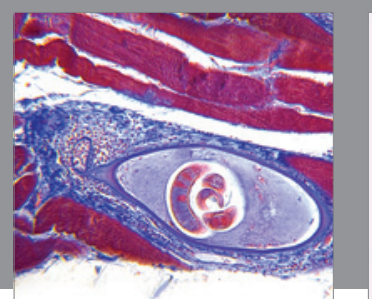

Gastroenterology Research and Practice

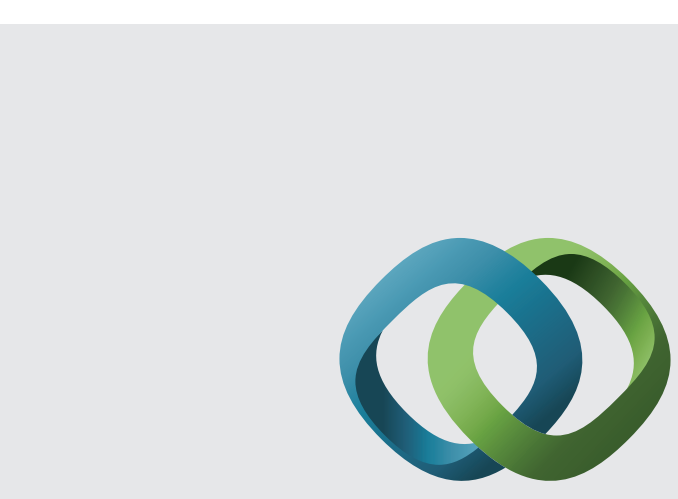

\section{Hindawi}

Submit your manuscripts at

http://www.hindawi.com
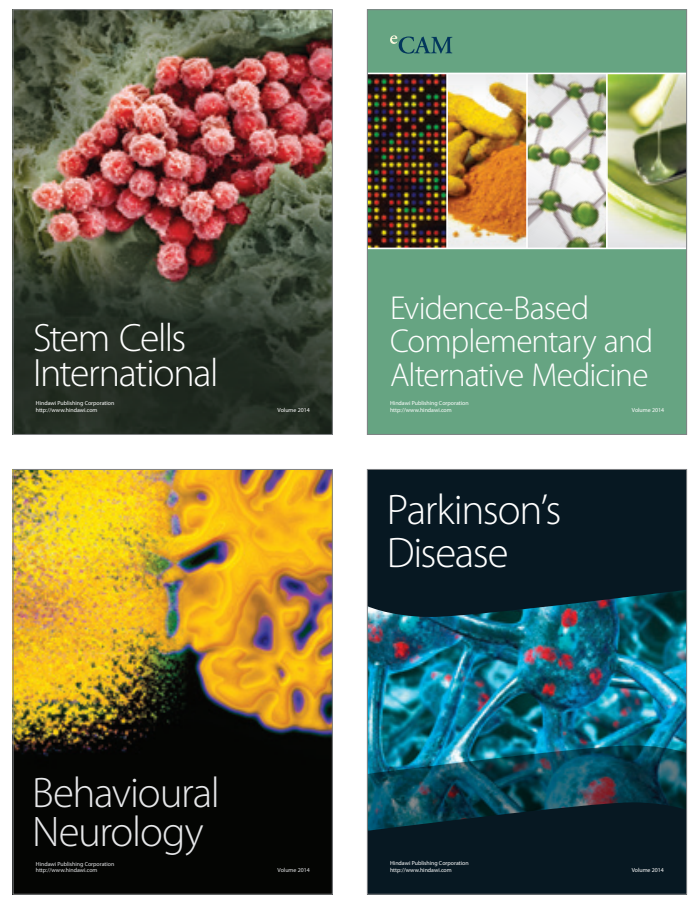
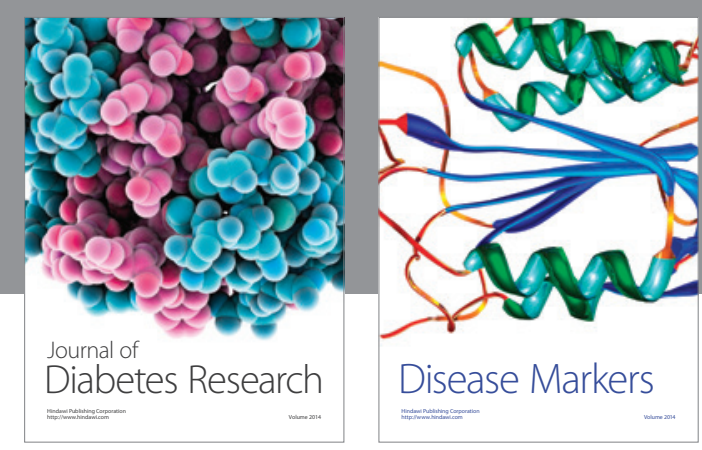

Disease Markers
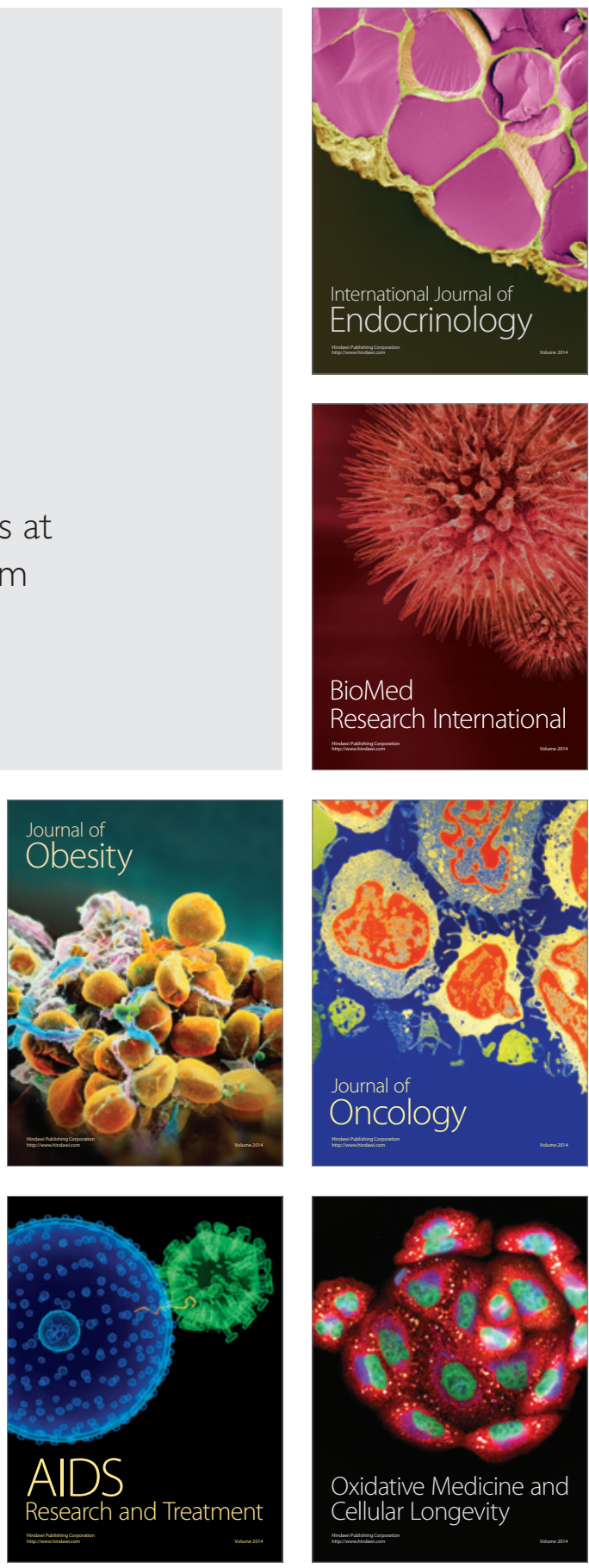